\title{
The Effect of Laughter Therapy on Anxiety, Depression and Stress of Cancer Patients Admitted to Long-Term Care Unit
}

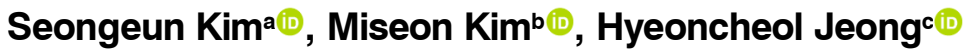 \\ ${ }^{a}$ Department of Nursing, Eden Adventist Hospital, Kyeongki, Republic of Korea \\ bepartment of Nursing, Munkyung College, Munkyung, Republic of Korea \\ ${ }^{c}$ Department of Nursing, College of Nursing, Sahmyook University, Seoul, Republic of Korea
}

Objective: This study is based on a parallax design before and after a non-equivalent control group to examine the effects of laughter therapy on the anxiety, depression, and stress in patients with cancer admitted to a nursing hospital.

Design: A randomized controlled trial.

Methods: Data collection was conducted on 34 patients who agreed to participate in the study among patients admitted to E Cancer Hospital from September to November 2018. Laughter treatment interventions were performed three times a week for 50 minutes each and a total of eight times. In this study, a tool developed by Spielberger was used to measure state anxiety, a tool developed by Beck was used to measure depression, and the Perceived Stress Scaled eveloped by Cohen was used to measure stress.

Results: Anxiety was significantly lower in the experimental group than in the control group $(\mathrm{F}=10.74, \mathrm{p}=0.003)$. Depression was lower in both the experimental group and the control group that did not participate in the laughter therapy intervention and was not significant $(\mathrm{F}=0.58, \mathrm{p}=0.451)$. Stress was significantly lower in the experimental group than in the control group ( $\mathrm{F}=4.36$, $\mathrm{p}=0.045)$.

Conclusions: The results of this study suggest that laughter therapy has a positive effect on reducing anxiety and stress in patients with cancer admitted to nursing hospitals.

Key Words: Laughter therapy, Neoplasm, Anxiety, Depression, Stress

\section{서론}

우리나라의 암 발생률은 2015년에 10만 명당 275.8명 으로 사망 원인 1 위이나 조기진단과 치료기술의 발전으로 암 환자의 5 년 생존율은 $70.7 \%$ 로 높아지고 있다[1]. 이는 암이 생명을 위협하는 질환일 뿐만 아니라 장기간 관리가 필요한 만성질환으로 전환되었음을 의미하는 것이다.

암 진단은 곧 죽음이라는 인식은 많이 없어졌어도 암 환자들은 여전히 다른 질병보다는 더 심각한 불안 정서반 응을 겪고 있다. 암 진단은 육체적, 심리적으로 매우 심각 한 변화를 일으키는 사건이기 때문에 자신감 상실과 불안 을 동반한 우울 증상을 보이기도 한다[2]. 암 환자에서 불
안과 우울은 흔히 나타난다고 하였는데, 암은 예상치 못 했던 경과를 밟는 경우가 있기 때문에, 환자는 자신의 신 체나 생활에 대한 조절능력이 없다는 사실에 실망하여 우 울에 빠지기도 하고, 여러 가지 검사, 치료, 합병증 등을 겪게 되면서 점차 의존적이 되거나 불안함을 느끼게 된다 [3].

암 환자가 가정에서 재활 및 관리하기에 식사, 휴식, 여가활동, 가족관계유지 등 일상생활에 어려움을 겪고 힘 들어 한다. 따라서 암 환자들을 대상으로 하는 전문요양 병원에 입원하여 다양한 보완대체요법을 포함한 재활프로 그램을 받으면서 요양생활을 한 후 다시 급성기 의료기관 에서 주기적인 치료를 받는 경우도 있다[4]. 이로 인해 전

Received: Jun 5, 2021 Revised: Jun 14, 2021 Accepted: Jun 16, 2021

Corresponding author: Hyeoncheol Jeong (ORCID https://orcid.org/0000-0001-8606-2373)

Department of Nursing, College of Nursing, Sahmyook University, Seoul, Republic of Korea

Hwarangro 815, Nowon-gu, Seoul, Republic of Korea [01795]

Tel: + 82-2-3399-1592 Fax: + 82-2-3399-1594 E-mail: love2hc@syu.ac.kr

This is an Open-Access article distributed under the terms of the Creative Commons Attribution Non-Commercial License (http://creativecommons.org/licenses/ by-nc/4.0) which permits unrestricted non-commercial use, distribution, and reproduction in any medium, provided the original work is properly cited.

Copyright $(\subset) 2021$ Korean Academy of Physical Therapy Rehabilitation Science 
문요양병원에 입원한 암 환자들은 의료기관의 의학적인 치료와 더불어 보완대체요법에 대한 관심이 증가하고 있 다. 암 환자를 대상으로 보완대체요법을 적용한 연구에는 마사지, 요가, 인지치료, 명상치료, 음악치료, 웃음치료 등 이 진행되어 왔다[5].

웃음치료는 암 환자들의 심리적인 문제를 해결하기 위 해 시도되고 있는 대체요법 중 하나로써[6], 다른 중재 보 다 특별한 준비나 비용이 들지 않으며 약간의 훈련만을 통해 어디서나 사용 가능하다는 장점이 있어 간호중재 방 안으로 널리 활용하고 있다[7]. 웃음은 긴장이나 불안과 같은 불쾌한 상황에서 벗어나게 하는 유용한 대처 전략으 로 암 환자의 스트레스 경감 뿐 아니라[8] 영적인 적응에 도 매우 유용한 것으로 보고되었다[6]. 또한 자연치유로 인한 면역성 및 저항력을 길러주기 때문에 질병 예방은 물론 건강을 개선하면서 몸을 강하게 만들고, 질병을 스 스로 치료할 수 있도록 남아있는 신체의 기능을 극대화하 여 신경계, 내분비계, 면역계, 호흡기계, 순환기계 등 신체 의 모든 기관에 관여한다[9]. 웃음으로 분비되는 엔돌핀은 통증 제거와 우울, 불안, 기분을 조절할 뿐만 아니라[10], 면역글로불린의 생성을 자극시키고, 자연 살해세포를 활 성화시키는 역할을 한다[6].

웃음에 관한 선행연구를 보면 웃음은 건강을 유지하고 스트레스, 우울 및 통증을 감소시키고[11], 마음을 편안하 게 하여 긴장을 완화시켜 불안 감소 및 면역력 향상에 긍 정적인 영향을 준다고 보고하였다[12].

웃음치료 중재에 관한 연구를 살펴보면 노인을 대상으 로 한 연구가 다수이며[8], 투석환자[13], 유류피해 지역 주민[14]등 다양한 대상자에게 웃음을 적용한 연구가 진 행되고 있다.

특히 암 환자를 대상으로 한 웃음치료에 대한 연구는 유머비디오를 이용한 암환자들의 불안, 우울에 관한 연구 [15], 유방암 환자[2,7,16], 부인과 암 환자[17]에게 적용 한 연구 등이 있으나, 요양병원에 입원하여 장기간 투병 생활을 이어가고 있는 암환자를 대상으로 그들의 주요한 심리적 문제인 불안, 우울, 스트레스를 측정한 연구는 아 직까지 국내에 거의 없었다.

따라서 본 연구는 요양병원에 입원한 암 환자를 대상으 로 웃음치료를 적용함으로써 그 효과를 확인하고, 추후 간호현장에서 적용하는데 필요한 기초 자료를 제공하기 위해 시도하였다.

\section{연구 방법}

\section{연구 대상}

본 연구의 대상자는 경기도 $\mathrm{E}$ 요양병원에 입원 중인
암 환자를 대상으로 연구 목적을 이해하고 연구 참여에 동의한 자를 선정하였다.

표본 수 산출은 $\mathrm{G}^{*}$ power 3.1.9.2를 이용해서 산출하였 고 $\mathrm{ANCOVA}$ 를 위한 대상자 수를 효과크기 0.80 , 유의수 준 $(\alpha) 0.05$, 검정력 $(1-\beta) \quad 0.80$ 으로 계산한 결과 각 집단 이 17 명씩 34 명으로 나왔다. 본 연구에서는 치료 방법 중 단일치료 요법과 병행치료 요법을 반영한 짝짓기 방법과 $20 \%$ 탈락률을 고려하여 실험군 20 명 대조군 20 명 총 40 명을 모집하였다. 구체적인 기준은 다음과 같다.

\section{참여기준}

- 설문지를 이해하고 응답할 수 있는 의사소통이 가능 한 환자

- 본 연구에 참여할 것을 서면으로 동의한 환자

- 웃음치료를 받아 본 경험이 없는 환자

\section{배제기준}

- 정신 질환자 혹은 인지 기능 장애 환자

- 청각에 이상이 있어 실험에 참여할 수 없는 환자

- 자신의 의사를 표현할 수 없는 의사소통이 불가능한 환자

\section{윤리적 고려}

본 연구는 연구자가 속해 있는 소속의 연구윤리위원회 (Institute of Research Board, IRB) 승인(임상 연구 과제 번호 : SYUIRB 2018-090)을 받았다. 연구 참여 대상자 에게 연구의 목적, 참여 기간, 진행 방법, 예상되는 위험 이나 이득, 익명성 유지에 대해 설명하였으며, 연구 참여 자가 원하지 않을 경우 연구에 참여한 이후에 언제든지 동의철회 할 수 있으며, 동의철회 하여도 그에 따른 어떤 불이익도 받지 않을 것임을 설명하였다. 연구에 참여한 대상자에게 소정의 답례품을 제공하였다.

\section{연구 절차}

본 연구는 요양병원에 입원한 암 환자를 대상으로 웃음 치료 중재 후 불안, 우울, 스트레스에 미치는 영향을 검증 하기 위한 비동등성 대조군 전후 시차설계에 의한 유사 실험연구이다.

본 연구의 자료 수집은 2018년 9월부터 11월 말까지 경기도 $\mathrm{E}$ 요양병원에 입원 중인 150 명의 암 환자 중 40 명을 편의표집 하였으며, 외생변수로 인한 영향을 최소화 하기 위해 치료 방법 중 수술, 항암요법, 방사선요법 중 단일요법을 시행하였거나, 2 가지 이상 병행요법 시행에 따라 실험군과 대조군을 짝짓기하여 배정하였다. 실험 기 
간 중 실험군, 대조군 각 3 명씩 중도 포기하여 최종적으 로 실험군 17 명, 대조군 17 명 총 34 명이 연구에 참여하였 다. 실험 처치의 확산으로 인한 오류를 방지하기 위해 대 조군은 9월, 실험군은 10 월부터 시기를 달리하여 진행하 였다.

실험군의 사후조사는 주 3 회, 3주 동안 8회차 웃음치료 중재가 끝난 후 사전과 동일한 설문지를 이용하여 불안, 우울, 스트레스를 자기기입방법으로 작성하게 하였다. 대 조군은 사전조사 3 주 후 실험군과 마찬가지로 설문을 작 성하게 하였으며, 실험이 끝난 후 웃음치료를 소개하고 참여 기회를 제공하였다.

\section{웃음치료 프로그램}

본 연구에서 실시한 웃음치료 프로그램은 이임선 등 [18]의 임상웃음치료 중 암 환자를 위한 웃음치료 프로그 램을 기반으로 본 연구자가 수정·보완하여 구성하였다. 프로그램 타당도 검증을 위해 간호학과 교수 1 인, 웃음 치료사 2 인, 요양병원 간호부장 1 인, 수간호사 1 인에게
프로그램 내용 타당성과 진행에 대한 자문을 구하였다. 웃음치료 진행은 웃음치료 1 급 자격증을 소지하고 $\mathrm{E}$ 요양 병원에서 웃음치료를 12 년째 진행 해 온 연구 보조원이 진행하였다. 실험군은 주 3 회 매 회당 50 분씩 총 8 회 집 단으로 웃음치료 중재를 하였다(Figure 1).

\section{측정 도구}

\section{불안}

Spielberger[19]가 개발한 State-Trait Anxiety Inventory 중 상태불안 측정 도구를 사용하였다. 총 20 문 항 중 10 개의 긍정문과 10 개의 부정문으로 구성되어 있 으며, Likert 4점 척도로 $1,2,5,7,10,11,15,16,19$, 20 번 긍정 문항은 역점수로 배점 하였다. 점수 범위는 최 소 20 점에서 최대 80 점이며 총점이 높을수록 불안 정도 가 높음을 의미한다. 도구 신뢰도는 Spielberger [19]의 도구개발 당시 Cronbach’ a값은 0.92였으며, 본 연구에서 는 Cronbach' a0.92 이였다.

\begin{tabular}{|c|c|c|c|}
\hline 단 계 & 순서 & 내용 & 시간(분) \\
\hline $\begin{array}{l}\text { 도입 } \\
\text { Introduction }\end{array}$ & 스트레칭 & 안면근육 풀기 & 10 \\
\hline \multirow[t]{2}{*}{$\begin{array}{l}\text { 전개 } \\
\text { Activity }\end{array}$} & 교육 & $\begin{array}{l}1 \text { 회 : 웃음에 관한 명언 } \\
2 \text { 회 : 웃음의 } 10 \text { 대 효과 } \\
3 \text { 회 : 웃음호흡 스트레칭 } \\
4 \text { 회 : 웃음의 기술 } \\
5 \text { 회 : 웃음과 눈물 } \\
\text { 6회 : 웃음의 사례 } \\
7 \text { 회 : 웃음지수 체크리스트 } \\
8 \text { 회 : 웃음 십계명 }\end{array}$ & 10 \\
\hline & 웃음운동 & $\begin{array}{l}\text { 건강박수 } \\
\text { 스킨십(안마하기) } \\
\text { 율동 따라하기 }\end{array}$ & 20 \\
\hline $\begin{array}{l}\text { 마무리 } \\
\text { Finish }\end{array}$ & 느낌 표현 & $\begin{array}{l}\text { 감정 표현 } \\
\text { 인사 하기 }\end{array}$ & 10 \\
\hline $\begin{array}{l}\text { 중재 } \\
\text { 모습 }\end{array}$ & & & \\
\hline
\end{tabular}

Figure 1. Program of laughter thrapy 
Table 2. Verification of Homogeneity of Measured Variables before Treatment $(n=34)$

\begin{tabular}{|c|c|c|c|c|}
\hline \multirow[t]{2}{*}{ Variables } & $\begin{array}{l}\text { Exp. } \\
(n=17)\end{array}$ & $\begin{array}{l}\text { Cont. } \\
(n=17)\end{array}$ & \multirow[t]{2}{*}{$\mathbf{t}$} & \multirow[t]{2}{*}{$\mathbf{p}$} \\
\hline & Mean(SD) & Mean(SD) & & \\
\hline Anxiety(score) & $35.47(8.63)$ & $39.53(12.33)$ & -1.11 & 0.274 \\
\hline Depression(score) & $8.24(5.62)$ & $11.18(6.82)$ & -1.37 & 0.180 \\
\hline Stress(score) & $13.06(6.17)$ & $13.53(4.54)$ & -2.53 & 0.802 \\
\hline
\end{tabular}

Values are presented as mean(SD)

Exp.: Experimental group, Cont.: Control group.

우울

Beck과 Steer[20]가 개발한 Beck Depression Inventory 를 이영호와 송종용[21]이 번안하여 표준화한 도구를 사 용하였다. 이 도구는 자기보고형 척도로 우울증의 정서적, 인지적, 동기적, 생리적 증상 영역을 포함하는 21 문항으로 구성되어 있다. 각 문항은 우울 정도에 따라 0점에서 3 점 까지 점수를 주며, 점수가 높을수록 우울 정도가 높음을 의미한다. Beck과 Steer[20]의 연구에서 Cronbach' $\alpha$ 값 은 0.93 이었고, 본 연구의 신뢰도 Cronbach' $\mathrm{a}$ 값은 0.80
이였다.

스트레스

Cohen 등 [21]이 개발한 Perceived Stress Scale을 이종하 등[13]이 수정·번안한 한글판 스트레스 자각 척도 를 사용하였다. 본 도구는 총 10 문항으로 구성되어 있으 며, Likert 5점 척도로 $4,5,7,8$ 번 부정 문항은 역점수로 총점이 높을수록 지각된 스트레스의 정도가 심한 것을 의 미한다. 이종하 등[13]의 연구에서 Cronbach' a 값은

Table 1. General Characteristics and the Homogeneity

$(n=34)$

\begin{tabular}{|c|c|c|c|c|c|}
\hline \multirow{2}{*}{ Characteristics } & & $\begin{array}{l}\text { Exp. } \\
(n=17)\end{array}$ & $\begin{array}{l}\text { Cont. } \\
(n=17)\end{array}$ & \multirow{2}{*}{$x^{2} / \mathbf{t}$} & \multirow{2}{*}{$\mathbf{p}$} \\
\hline & & $\begin{array}{l}\text { n(\%) or } \\
\text { Mean(SD) }\end{array}$ & $\begin{array}{l}\text { n(\%) or } \\
\text { Mean(SD) }\end{array}$ & & \\
\hline \multirow[t]{2}{*}{ Sex } & Male & $5(29.4)$ & $7(41.2)$ & 0.56 & 0.473 \\
\hline & Female & $12(70.6)$ & $10(58.8)$ & & \\
\hline Age (years) & & $60.00 \pm 11.04$ & $53.65 \pm 8.90$ & 1.85 & 0.074 \\
\hline \multirow[t]{4}{*}{ Diagnosis of cancer } & GI system & $8(47.1)$ & $6(35.3)$ & - & $0.957^{*}$ \\
\hline & Urogenital system & $2(11.8)$ & $2(11.8)$ & & \\
\hline & Breast & $3(17.6)$ & $5(29.4)$ & & \\
\hline & Other & $4(23.5)$ & $4(23.5)$ & & \\
\hline \multirow[t]{3}{*}{ Stage } & $1-2$ & $6(35.3)$ & $2(11.8)$ & - & $0.250^{*}$ \\
\hline & 3 & $6(35.3)$ & $7(41.2)$ & & \\
\hline & 4 & $5(29.4)$ & $8(47.0)$ & & \\
\hline \multirow[t]{3}{*}{ Treatment } & Single & $6(35.3)$ & $6(35.3)$ & - & $1.000^{*}$ \\
\hline & Combination & $9(52.9)$ & $9(52.9)$ & & \\
\hline & None & $2(11.8)$ & $2(11.8)$ & & \\
\hline
\end{tabular}

Values are presented as $\mathrm{n}(\%)$ or mean(SD)

Exp.: Experimental group, Cont.: Control group, GI:Gastrointestinal.

* Fisher's exact test 
0.81 이었으며, 본 연구의 신뢰도 Cronbach' a값은 0.78이 었다.

\section{자료 분석}

본 연구의 자료 분석은 SPSS/WIN Ver. 25 통계프로 그램을 이용하여 분석하였다.

- 대상자의 일반적 특성은 빈도와 백분율, 평균과 표준 편차로 하였으며, 동질성 검증은 -test, t-test, Fisher's exact test를 이용하여 분석하였다.

- 두 군간의 웃음치료 후 불안, 우울, 스트레스 차이는 결과값의 정확도를 높이기 위해 사전 값을 공변값으 로 처리하여 ANCOVA로 분석하였다.

- 측정도구의 신뢰도 검증은 Cronbach's $\alpha$ 로 검정하였다.

- 통계의 유의수준은 양측검정에서 $\mathrm{p}<.05$ 로 하였다.

\section{연구결과}

\section{대상자의 일반적 특성 및 동질성 검증}

일반적 특성을 분석한 결과 성별, 연령, 진단명, 병기, 치료방법 에 대해서 통계적으로 동질하게 나타났다(Table 1). 또한 대상자의 중재 전 측정 변수에 대한 동질성 검증 을 한 결과 두 군간에 불안, 우울, 스트레스 모두 동질한 것으로 나타났다(Table 2).

\section{웃음치료가 불안, 우울, 스트레스에 미치는 효과}

웃음치료 중재에 참여한 실험군이 참여하지 않은 대조 군에 비해 불안 점수가 통계적으로 유의하게 감소하였다 $(\mathrm{F}=10.74, \mathrm{p}=0.003)$.

웃음치료 중재에 참여한 실험군과 참여하지 않은 대조 군 모두 우울 점수가 낮아졌으나 통계적으로 유의하지 않 았다 $(\mathrm{F}=0.58, \mathrm{p}=0.451)$.

웃음치료 중재에 참여한 실험군이 참여하지 않은 대조 군에 비해 스트레스점수가 통계적으로 유의하게 감소하였 다 $(\mathrm{F}=4.36, \mathrm{p}=0.045)($ Table 3$)$.

Table 3. The Effect of Laughter Therapy

$(n=34)$

\begin{tabular}{|c|c|c|c|c|c|}
\hline Variables & & $\begin{array}{l}\text { Pre } \\
\text { Mean(SD) }\end{array}$ & $\begin{array}{l}\text { Post } \\
\text { Mean(SD) }\end{array}$ & $F^{*}$ & $\mathbf{p}$ \\
\hline \multirow{2}{*}{$\begin{array}{l}\text { Anxiety } \\
\text { (score) }\end{array}$} & $\begin{array}{l}\text { Exp. } \\
(n=17)\end{array}$ & $35.47(8.63)$ & $28.18(8.05)$ & \multirow{2}{*}{10.74} & \multirow{2}{*}{0.003} \\
\hline & $\begin{array}{l}\text { Cont. } \\
(n=17)\end{array}$ & $39.53(12.33)$ & $38.41(12.09)$ & & \\
\hline \multirow{2}{*}{$\begin{array}{l}\text { Depression } \\
\text { (score) }\end{array}$} & $\begin{array}{l}\text { Exp. } \\
(n=17)\end{array}$ & $8.24(5.62)$ & $5.65(4.36)$ & \multirow{2}{*}{0.58} & \multirow{2}{*}{0.451} \\
\hline & $\begin{array}{l}\text { Cont. } \\
(n=17)\end{array}$ & $11.18(6.82)$ & $8.82(7.57)$ & & \\
\hline \multirow{2}{*}{$\begin{array}{l}\text { Stress } \\
\text { (score) }\end{array}$} & $\begin{array}{l}\text { Exp. } \\
(n=17)\end{array}$ & $13.06(6.17)$ & $10.47(4.23)$ & \multirow{2}{*}{4.36} & \multirow{2}{*}{0.045} \\
\hline & $\begin{array}{l}\text { Cont. } \\
(n=17)\end{array}$ & $13.53(4.54)$ & $12.88(4.46)$ & & \\
\hline
\end{tabular}

Values are presented as mean(SD)

Exp.: Experimental group, Cont.: Control group.

*ANCOVA results with covariate pre-test 


\section{고찰}

본 연구는 요양병원에 입원한 암 환자를 대상으로 웃음 치료 중재 후 불안, 우울 및 스트레스에 미치는 영향을 검 증하기 위해 시도되었다. 본 연구의 결과를 근거로 하여 논의하고자 한다.

본 연구에서 웃음치료 중재가 요양병원에 입원한 암 환 자의 불안에 미치는 영향을 살펴본 결과 웃음치료가 암 환자의 불안 감소에 영향을 미치는 것으로 나타났다. 방 사선요법을 받는 유방암 여성을 대상으로 $50 \sim 60$ 분간 주 2 회 총 4 회의 웃음요법을 적용한 김소희 등[2]의 연구에 서도 웃음요법이 불안을 통계적으로 유의하게 감소하여 본 연구 결과와 일치하였다. 유방절제술 후 환자를 대상 으로 매일 1 회 총 5 회기로 대상자의 병실을 방문하여 약 30 분간 웃음요법을 실시 한 유은숙과 최연희[22]의 연구 에서도 실험군의상태불안 수준은 유의하게 감소된 것으로 나타나 본 연구 결과와 일치하였다. 척추수술 환자를 대 상으로 입원 2일째부터 매일 1회 퇴원 전 까지 대상자의 병실을 방문하며 약 15 분 30 분 동안 웃음중재를 실시 한 양미선[23]의 연구에서도 실험군의상태불안이대조군에 비해 유의하게 낮아진 것으로 나타나 본 연구 결과와 유 사하였다. 반면에 노인 대상자에게 일회성 웃음요법을 적 용한 김영선과 전성숙[8]의 연구에서는 불안 감소에 통계 적으로 유의한 변화는 없었으며, 김경희와 이명화[24]의 연구에서는 혈액 투석환자에게 20 30분간 3회차 유머 비디오를 시청하도록 하였으나 통계적으로 유의한 변화가 없었다. 김희진과 서문자[25]의 연구에서도 기동성 장애 환자에게 20 분간 3 회차 유머 비디오를 시청하도록 했으나 대상자의 불안수준이 약간 감소하였으나 통계적으로 유의 하지 않아 본 연구결과와 일치하지 않았다. 이는 단기간 혹은 일회성의 웃음치료 방법이 상태불안 감소에 효과적 이지 않아 보이며, 특히 김경희와 이명화[24]의 연구에서 는 연구 대상자가 혈액 투석 기간이 1 년 이상 경과한 대 상자들로 심리적으로 다소 안정된 상태이거나 장기적인 적응에 들어갔기 때문에 웃음치료가 상태불안에 영향을 미치지 못했던 것으로 생각된다.

본 연구에서 웃음치료 중재가 암 환자의 우울에 미치는 영향을 살펴본 결과 우울 감소에 영향을 미치지 않는 것 으로 나타났다. 조은아[16]의 유방암 환자를 대상으로 60 분간 주 2회 4주 동안 8 회의 웃음 중재를 적용 한 연구에 서 우울 정도는 통계적으로 유의한 차이가 없어 본 연구 결과와 일치하였다. 김경희와 이명화[24]의 연구에서도 웃음중재 적용이 우울 감소에 효과가 없는 것으로 나타나 본 연구 결과와 일치 하였다. 또 유류피해 지역 주민을 대 상으로 주 1회 4주간 60 분씩 웃음치료 프로그램을 제공 한 이용미와 손정남[14]의 연구에서는 우울 감소에 통계
적으로 유의한 결과가 나타나지 않아 본 연구 결과와 일 치하였다. 반면에 부인과암 환자를 대상으로 주 1 회 60 분 간 8 회의 웃음 중재를 적용한 이용진[17]의 연구에서는 우울 점수가 실험군이 대조군에 비해 유의하게 감소하여 본 연구 결과와 상반되었다. 이는 우울이 웃음치료 중재 기간과 환자성향에 따라서 차이가 있는 것으로 보이며, 우울은 다른 변수들과 달리 병리학적인 특성을 가지고 있 기 때문에 단기간의 간호중재를 통해서는 우울 감소에 영 향을 미치지 못하는 것으로 여겨진다. 또 본 연구 대상자 특성에서 실험군의 경우 사전 점수가 평균 8점으로 우울 하지 않는 상태였으며, 자발적으로 연구 참여에 승낙한 점을 고려할 때 좀 더 적극적이고 긍정적인 성격의 소유 자일 가능성이 높아 우울정도에는 유의한 변화가 없었던 것으로 사료된다.

본 연구에서 웃음치료 중재가 암 환자의 스트레스에 미 치는 영향을 살펴본 결과 웃음치료가 암 환자의 스트레스 감소에 영향을 미치는 것으로 나타났다. 김소희 등[2]의 연구에서도 대조군 대비 실험군의 스트레스 정도가 유의 하게 감소되어 스트레스 개선에 효과가 있어 본 연구 결 과와 유사하였다. 이용진[17]의 연구에서도 스트레스 점 수가 실험군이 대조군에 비해 통계적으로 유의하게 감소 하였으며, 최정화 등[7]의 유방절제술 환자를 대상으로 주 4회 2주 동안 총 8 회의 웃음치료를 실시 한 연구에서도 실험군의 스트레스 점수가 유의하게 감소하여 본 연구 결 과와 일치하게 나타났다. 반면 화상병원 간호사를 대상으 로 주 1 회 총 8 회의 웃음치료를 적용한 오은영 등[26]의 연구에서는 스트레스 대처척도는 통계적으로 유의한 차이 를 보이지 않아 본 연구 결과와 상반되었다. 이는 실험 전 부터 대상자의 스트레스 점수가 높지 않았기 때문에 실험 후에 유의한 변화를 가져오지 않았던 것으로 생각된다.

이상과 같이 웃음치료는 긴장이나 불안과 같은 불쾌한 상황에서 벗어나게 하는 유용한 대처 전략으로 웃음치료 시 엔도르핀 분비가 증가되어 통증과 마음이 편안하게 된 다. 이로 인해 긴장을 감소되어 불안과 스트레스 같은 불 쾌한 상황에서 벗어나게 한 것이라 생각된다.

\section{결론}

본 연구결과 요양병원에 입원한 암환자에게 웃음치료 중재가 불안과 스트레스 감소에 효과가 있음이 규명되었 다. 따라서 다른 중재법보다 특별한 준비나 비용이 들지 않으며, 시간과 장소에 구애 받지 않는 웃음치료는 요양 병원에 입원한 암 환자에게 적용하기 편리한 중재 방법이 라 할 수 있겠다.

본 연구의 결과를 토대로 다음과 같은 제언을 하고자 
한다.

- 대상자를 암 질환이나 병기에 따른 연구가 필요하다.

- 암 환자를 대상으로 다른 보완대체 요법과 웃음치료 의 비교 연구가 필요하다.

\section{이해 충돌}

본 연구의 저자들은 연구, 저자권, 및 출판과 관련하여 잠재적인 이해충돌이 없음을 선언합니다.

\section{참고문헌}

1. National Cancer Information Center. Cancer incidence. Goyang (Republic of Korea); 2017.

2. Kim SH, Kim YH, Kim HJ, Lee SH, Yu SO. The effect of laughter therapy on depression, anxiety, and stress in patients with breast cancer undergoing radiotherapy. Asian Oncology Nursing. 2009;9:155-62.

3. Kim BR, Kim YH, Kim JS, Jeong IS, Kim JS.A Study to the coping patterns of cancer patients. J Korean AcadNurs. 2003;33:321-30.

4. Hong SJ, Lee HH. Effects of naturopathic treatments of koreancancer patients. Journal of Naturopathy. 2013;2:154-63.

5. Park JS, Oh YJ. Development and evaluation of the psychosocial distress nursing intervention for patients with gynecological cancer. The Journal of Korean Academic Society of Adult Nursing. 2012;24:219-31.

6. Berk LS, Felten DL, Tan SA, Bittman BB, Westengard J. Modulation of neuroimmune parameters during the eustress of humor-associated mirthful laughter. Altern Ther Health Med. 2001;7:62-72, 4-6.

7. Choi JH, Kim KH, Cha SJ, Pyo HJ, Kim YK. Effects of laughter therapy on mood, pain, and stress of mastectomy patients. J Korean Clin Nurs Res. 2010;16:83-93.

8. Kim YS, Jun SS. The influence of one-time laughter therapy on stress response in the elderly. J Korean AcadPsychiatrMent Health Nurs. 2009;18:269-77.

9. Fry WF, Jr. The physiologic effects of humor, mirth, and laughter. JAMA. 1992;267:1857-8.

10. Miller M, Fry WF. The effect of mirthful laughter on the human cardiovascular system. Med Hypotheses. 2009;73:636-9.
11. Penson RT, Partridge RA, Rudd P, Seiden MV, Nelson JE, Chabner BA, et al. Laughter: the best medicine? Oncologist. 2005;10:651-60.

12. Christie W, Moore C. The impact of humor on patients with cancer. Clin J Oncol Nurs. 2005;9:211-8

13. Lee JH, Shin CM, Ko YH, Lim JH, Joe SH, Kim $\mathrm{SH}$, et al. The reliability and validity studies of the Korean version of the perceived stress scale. Korean J Psychosom Med. 2012;20:127-34.

14. Lee YM, Sohn JN. The effects of laughter therapy on anger, anger expressions and mental status after oil spill in victimized community residence. J Korean AcadPsychiatrMent Health Nurs. 2010;19:186-95.

15. Suh MJ, Kim KS. Effect of humor nursing intervention on the stress response for the cancer patient undergoing chemotherapy. Korean J Stress Res. 1994;2:193-206.

16. Cho EA. Effects of laughter therapy on depression, quality of life, resilience and immune responses. Gwangju: Chosun University; 2010.

17. Lee YJ. The effect of laughter therapy program on stress, depression and quality of life of patients with gynecological cancer. Pocheon: Cha University; 2016.

18. Lee IS, Bae KH, Baek JS. Laughter therapy. Seoul: Changjisa; 2009.

19. Spielberger CD. Anxiety: state-trait process. Stress and Anxiety. 1975;1:115-43.

20. Beck AT, Steer RA. Manual for the Beck Anxiety Inventory. Texas: Psychological Corporation; 1990.

21. Cohen S, Kamarck T, Mermelstein R. A global measure of perceived stress. J Health Soc Behav. 1983;24:385-96.

22. You ES, Choi YH. The effects of laughter therapy on pain and anxiety among patients with postmastectomy. J. East-West Nurs. Res. 2012;18:47-52.

23. Yang MS. The effects of laughter therapy on pain and state anxiety of spinal surgery patients. Jeonju: Jeonbuk National University; 2008.

24. Kim KH, Lee MH. Effects of humor intervention program on anxiety, depression and coping of humor in hemodialysis patients. Korean Academic Society of Rehabilitation Nursing. 1999;2:95-108.

25. Kim HJ, Suh MJ. Effect of humor video tape on an anxiety, depression and coping of the impaired mobility patient. The Seoul Journal of Nursing. 
1996;10:203-17.

26. Oh EY, Kang KH, Son OL, Wo MA, Lee MS, Kim

SJ. The effects of laughter therapy on stress response and coping for specialized burn hospital nurses. Korean Journal of Stress Research. 2011;19:323-31. 